\title{
LITÍGIOS DE CONSUMO NAS RELAÇÕES TRANSFRONTEIRIÇAS - INJUNÇÃO EUROPEIA E PROCESSO EUROPEU PARA ACÇÕES DE PEQUENO MONTANTE NA ERA DA E-JUSTICE ${ }^{1}$
}

\author{
CONSUMER LITIGATION IN CROSS-BORDER TRANSACTIONS - EUROPEAN \\ ORDER FOR PAYMENT AND EUROPEAN SMALL CLAIMS PROCEDURE IN THE \\ E-JUSTICE AGE
}

Lurdes Varregoso Mesquita Doutora em Direito, Professora Auxiliar do Departamento de Direito da Universidade Portucalense, Professora Adjunta Convidada da Escola Superior de Tecnologia e Gestão do Instituto Politécnico do Porto, Investigadora do Instituto Jurídico Portucalense. Portugal. E-mail: lvm@upt.pt

\begin{abstract}
RESUMO: O aumento das relações de consumo no mercado europeu potencia a litigiosidade transfronteiriça. A União Europeia, atenta a esta realidade, tem procurado criar as medidas e os instrumentos necessários a atenuar as dificuldades próprias dos conflitos plurilocalizados, numa atitude responsável de tutela do direito de acesso à justiça. Neste contexto, o presente trabalho pretende avaliar, no quadro judicial europeu, de que forma o processo europeu aplicado aos litígios de consumo tem evoluído, em especial na sua eficácia, através do uso das tecnologias de informação, ou seja, no âmbito da justiça electrónica. Efectivamente, o uso dos meios electrónicos nos procedimentos europeus de segunda geração - em especial na injunção europeia e no processo europeu para acções de pequeno montante - tem sido reforçado, procurando aliar os sistemas de informação aos processos, de forma a proporcionar acessibilidade e celeridade. Apesar desse esforço, os procedimentos europeus para litígios transfronteiriços não têm ocupado um lugar expressivo nas opções dos operadores forenses. Embora se conclua que a $e$-justice pode contribuir para a eficácia e celeridade dos processos europeus, constata-se que, em contraciclo, há alguma resistência à sua utilização. Há vantagens reconhecidas nestes instrumentos europeus, mas a sensibilidade jurídico-cultural para a sua
\end{abstract}

\footnotetext{
${ }^{1}$ Artigo recebido em 03/06/2021, sob dispensa de revisão.
} 
efectiva utilização é variável, na arquitectura judicial europeia, o que tem contribuído para um desequilíbrio dos sistemas.

PALAVRAS-CHAVE: E-Justice, relações de consumo, litígios transfronteiriços, procedimentos europeus de cobrança, small-claims.

\begin{abstract}
The increase of consumer relations in the European market potentiates crossborder litigation. The European Union, aware of such reality, is trying to create necessary measures and instruments to mitigate difficulties related to multi-located conflicts. This attempt represents a responsible attitude to guarantees access to justice. In this context, the present paper aims to evaluate, in the European judicial frame, the evolution of the procedure - applied to consumer disputes -, in particular in their effectiveness, through the use of technologies (in the context of the e-Justice). The use of electronic devices in the European procedures (in particular concerning the European injunction and in small claims) has been reinforced, in an attempt to ally the procedural information systems to promote the accessibility and celerity. However, the European procedures related to cross-border lawsuits have not taken an expressive place in the law operators' options. Even that we consider that the e-Justice may contribute to the efficacy and celerity of the European lawsuits, we have a counter cycle that resists its use. There are many recognized advantages to this kind of instrument. Although, the juridical-cultural sensitivity for effective use of these instruments is uncertain in the European judicial architecture, which contributes to a system imbalance.
\end{abstract}

KEYWORDS: E-Justice, consumer relations, cross-border lawsuits, European collection procedures, small-claims.

Sumário: I. Nota introdutória; II. E-Justice no Espaço Europeu de Justiça; 1. Contexto e emergência do fenómeno na União Europeia; 2. Enquadramento legal; 3. Âmbito e áreas de actuação; 4. Desafios da justiça electrónica num contexto de diversidade jurídico-cultural; III. Relações de consumo e litígios transfronteiriços - as TIC como instrumento de eficácia e celeridade; 1 . Protecção das relações de consumo na União Europeia; 2. Relações de consumo e litígios transfronteiriços; 3. Os procedimentos europeus de segunda geração aplicáveis aos 
litígios de consumo transfronteiriços; 4. Mecanismos procedimentais e e-justice; 5. Avaliação da utilização dos procedimentos europeus no espaço europeu de justiça; IV. Conclusões.

\section{Nota introdutória}

União Europeia, consumo, era digital e processo são realidades actuais e indissociavelmente relacionadas no cenário do espaço europeu de justiça ${ }^{2}$, onde tem prevalecido o princípio do reconhecimento mútuo, como forma de esbater as fronteiras jurídicas. Tudo isto tem especial relevância no âmbito das relações de consumo, em defesa dos consumidores e das empresas, considerados elementos centrais do desenvolvimento económico do mercado único europeu. Mas, também, potenciadores do aumento da litigiosidade, em especial a transfronteiriça, em consequência do maior número de transacções económicas plurilocalizadas.

Neste contexto, porque o adequado funcionamento do sistema judicial na satisfação célere e efectiva dos direitos dos consumidores e das empresas é um dos factores que favorece o crescimento económico, a União Europeia tem criado mecanismos que contribuem para a concretização desse objectivo. O procedimento europeu de injunção de pagamento, assim como o processo europeu para acções de pequeno montante tiveram a sua origem assente nestes pressupostos e constituíram etapas marcantes na construção do espaço europeu de justiça, no aprofundamento da cooperação judiciária civil $^{3}$. Estes meios para-judicias e judiciais são considerados procedimentos de segunda geração porque aliam a aplicação directa nos ordenamentos dos Estados-Membros de procedimentos europeus, alternativos aos mecanismos internos, utilizados na resolução de litígios transfronteiriços, à emissão de decisões com efeito

\footnotetext{
${ }^{2}$ Foi no Tratado de Amesterdão que se deu a comunitarização da matéria da cooperação judiciária, a qual passou a integrar o primeiro pilar, deixando as soluções meramente intergovernamentais. A criação do espaço de liberdade, de segurança e de justiça baseia-se numa tríade de conceitos indissociáveis, que têm como denominador comum as «pessoas» e que só se podem realizar plenamente quando todos estão em equilíbrio e sintonia. A liberdade só faz sentido quando vivida num ambiente de segurança, solidamente assente num sistema de justiça no qual todos os cidadãos e residentes da União possam ter confiança. Esta ideia ficou plasmada no Plano de Acção de Viena (ponto 5), publicado no JO C 19/1, de 23.01.1999.

${ }^{3}$ O título executivo europeu, criado pelo Regulamento 805/2004, de 21 de abril, fez igualmente parte desta evolução no Direito Processual Civil Europeu. Trata-se de um procedimento através do qual são certificados títulos executivos nacionais (decisões judiciais, transacções judiciais e instrumentos autênticos) que passam a ter força executiva a nível do espaço europeu, no contexto dos créditos não contestados, tendo em vista a sua execução num outro Estado que não aquele em que se deu a formação do título executivo, sem recurso a mais procedimentos intermédios, ou seja, sem necessidade do tradicional procedimento de exequatur no Estado de execução.
} 
executório imediato em todo o espaço europeu, com abolição do exequatur. E são estes procedimentos que, para além dos meios alternativas de resolução de litígios ${ }^{4}$, sustentam uma nova vaga na defesa dos direitos dos consumidores e das empresas.

As tecnologias da informação e comunicação (TIC), por sua vez, são consideradas um instrumento valioso na consolidação dos referidos objectivos. A cooperação judiciária civil no espaço europeu suporta-se, cada vez mais, na justiça electrónica. A e-justice, sustentada na utilização das TIC ao serviço dos sistemas de justiça dos Estados-Membros, em especial em situações com incidência transfronteiras, tem em vista possibilitar um acesso mais fácil à justiça e melhor informação judiciária aos cidadãos, empresas e profissionais da justiça, bem como facilitar a cooperação entre as autoridades judiciárias dos Estados-Membros.

A questão que se coloca e para a qual se pretende contribuir com a presente análise, é a de saber de que modo as TIC contribuem para promover a eficácia e celeridade dos procedimentos criados pela União Europeia para as empresas e cidadãos satisfazerem os seus direitos em caso de litígios que tenham na sua base relações de consumo ${ }^{5}$.

\section{E-Justice no Espaço Europeu de Justiça}

\section{Contexto e emergência do fenómeno na União Europeia}

Globalização, mercado único e era digital são facetas da vida contemporânea que se interrelacionam e, cada vez mais, condicionam a evolução da justiça a uma velocidade não comparável com o estado da arte há cerca de duas décadas. Nenhuma área jurídica fícou

\footnotetext{
${ }^{4}$ A União Europeia não esteve alheia ao fenómeno dos Alternative Dispute Resolution. Desde o Plano de Acção de Viena e do Conselho Europeu de Tampere que a questão dos meios de resolução alternativa de litígios é apontada como objectivo a alcançar através da sua difusão e progressiva implementação quer a nível interno, quer a nível das relações transfronteiriças. Veja-se, designadamente em matéria civil e comercial, a Directiva 2008/52/CE do Parlamento Europeu e do Conselho (JO L 136/3, de 24.5.2008) e, para análise do seu impacto: o "Rebooting" the Mediation Directive: Assessing the limited impact of its implementation and proposing measures to increase the number of mediations in the EU, 2014, disponível em http://www.europarl.europa.eu/RegData/etudes/etudes/join/2014/493042/IPOL-

JURI_ET(2014)493042_EN.pdf; o Relatório da Comissão ao Parlamento Europeu, ao Conselho e ao Comité Económico e Social Europeu, sobre a aplicação da Directiva 2008/52 (COM (2016) 542 final, 26.8.2016); Relatório do Parlamento Europeu sobre a aplicação da Directiva 2008/52/CE, (2016/2066 (INI)), de 27.6.2017, A8-0238/2017.

${ }^{5}$ As relações de consumo têm origem em contratos de consumo, onde um dos contraentes é considerado consumidor, isto é, aquele a quem sejam fornecidos bens, prestados serviços ou transmitidos quaisquer direitos, destinados a uso não profissional, por pessoa que exerça com carácter profissional uma actividade económica que vise a obtenção de benefícios (cfr. art. . $^{\circ}$, n. ${ }^{\circ}$ 1, da Lei de Defesa do Consumidor, aprovada pela Lei n. ${ }^{\circ}$ 24/96, de 31 de julho). Embora não exista um conceito único de «consumidor», esta é a definição de referência no ordenamento jurídico português. Sobre esta matéria, vide CARVALHO, J. M., Manual de Direito do Consumo, 4. ${ }^{a}$ edição, Coimbra: Almedina, 2017, pp. 21-30.
} 
indiferente aos desafios da modernidade, seja por via da eliminação das fronteiras físicas, com a livre circulação de bens, serviços, capitais e pessoas, seja através da evolução das TIC. Estes dois factores concorreram para o desenvolvimento económico, para a melhor qualidade de vida dos cidadãos europeus, incrementaram a procura e a troca de bens e serviços, libertaram as pessoas das barreiras físicas, proporcionaram a evolução cultural através de uma maior partilha de conhecimento e alteraram os padrões sociais. Porém, reflexamente, aumentaram a base da pirâmide de litigiosidade. E por isso, os «novos tempos» pedem resultados céleres e satisfação imediata da tutela judicial efectiva, assente em parâmetros que, sem pôr em causa a realização da Justiça e as garantias dos cidadãos, atenuem as barreiras inerentes à tramitação dos processos e às comunicações em suporte físico. Por outro lado, exige-se que os sistemas judiciais dos Estados-Membros trabalhem em rede.

Neste contexto, em 2001, integrada na cooperação judiciária em matéria civil e $\operatorname{comercial}^{6}$, a União Europeia criou a Rede Judiciária Europeia em matéria civil e comercial ${ }^{78}$. Com vista a melhorar o acesso dos cidadãos e das empresas à justiça na Europa, sobretudo quando confrontados com qualquer tipo de litígio «transfronteiras», criou-se uma rede de autoridades nacionais competentes no domínio do direito civil e comercial, composta por representantes das autoridades judiciárias e administrativas dos Estados-Membro, com o intuito de trocar informações e experiências e reforçar a cooperação entre os Estados-Membros no domínio do direito civil e comercial ${ }^{9}$. Esta estrutura de cooperação em rede tinha como objectivo primordial a disponibilização de informação acessível ao público, de forma a facilitar a vida daqueles que se vejam confrontadas com litígios transfronteiriços. Em consequência, beneficia-se a cooperação judiciária no domínio civil e comercial entre os Estados-Membros,

\footnotetext{
${ }^{6}$ Inserida nas políticas de criação do espaço de liberdade, segurança e justiça, a cooperação judiciária em matéria civil e comercial tem a tarefa de contribuir para uma colaboração próxima entre as autoridades dos EstadosMembros a fim de eliminar quaisquer obstáculos decorrentes das incompatibilidades existentes entre os diferentes sistemas judiciários e administrativos.

${ }^{7}$ Decisão do Conselho de 28 de maio de 2001 (2001/470/CE), publicada no JO L 174 de 27.6.2001.

${ }^{8}$ Para análise dos resultados, ver o Relatório da Comissão ao Conselho, ao Parlamento Europeu e ao Comité Económico e Social Europeu sobre a aplicação da Decisão n. ${ }^{\circ}$ 2001/470/CE do Conselho que cria uma rede judiciária europeia em matéria civil e comercial, SEC (2006) 579 (COM/2006/0203 final de 16.05.2006).

${ }_{9}^{9}$ Sobre a Rede Judiciária Europeia, cfr. Comentário de BEERGREHN, Ulrika, in "Conselho da União Europeia, Direito Civil, Cooperação Judiciária Europeia”. Luxemburgo: Serviço das Publicações Oficiais das Comunidades Europeias, 2005, p. 261-270.
} 
assim como os cidadãos, através de uma cooperação melhor e mais eficaz entre as autoridades competentes ${ }^{10}$.

Em Junho de 2007, após o trabalho levado a cabo pelo Grupo da Informática Jurídica (Legal Data Processing), o Conselho de Justiça e Assuntos Internos deu o primeiro impulso para a criação e consolidação da e-justice ${ }^{11}$. Já nessa data, ficou definido que apenas estavam incluídas as questões de natureza transfronteiriça e foram avançadas as áreas prioritárias e alguns objectivos concretos. As funções essenciais do sistema da justiça electrónica estavam traçadas: i) acesso às informações no domínio da justiça; ii) desmaterialização dos procedimentos; iii) comunicações entre autoridades judiciárias. No que respeita aos processos judiciais, foram apontados os actos que podiam ser abrangidos, designadamente: propositura da acção, notificações, remessa de documentos, comunicação entre tribunais, vídeoconferência. Além disso, a injunção europeia, as small claims e a decisão europeia de arresto de contas ficaram, desde logo, assinaladas como sendo os processos europeus de aplicação prioritária dos mecanismos electrónicos.

As demais instituições europeias associaram-se ao projecto de criação e desenvolvimento de instrumentos de justiça electrónica: a Comissão apresentou a sua comunicação "Rumo a uma estratégia europeia em matéria de justiça electrónica"12; o Parlamento Europeu adoptou uma resolução sobre a justiça electrónica, a 18 de dezembro de $2008^{13}$, onde apelava à criação de um adequado instrumentário para assegurar que a futura legislação fosse concebida com vista à sua utilização em linha. Adoptou ainda uma resolução sobre justiça electrónica na sessão plenária de 22 de outubro de $2013^{14}$, chamando a atenção para o maior uso das aplicações electrónicas, do fornecimento de documentos por via electrónica, do uso da videoconferência e da interligação dos registos judiciários e administrativos, com vista a reduzir significativamente as custas dos processos judiciais e extrajudiciais.

\footnotetext{
${ }^{10}$ Ainda hoje está activo o Ponto de Contacto de Portugal na Rede Judiciária Europeia, em matéria civil e comercial (RJE-civil), em http://www.redecivil.mj.pt/.

${ }^{11} \mathrm{Cfr}$. o documento de apresentação das conclusões do trabalho em

http://register.consilium.europa.eu/doc/srv?l=EN\&f=ST\%2010393\%202007\%20INIT (consultado a 01 de fevereiro de 2018).

${ }^{12} \operatorname{COM}(2008) 329$ final.

${ }^{13}[2008 / 2125($ INI)].

${ }^{14}[2013 / 2852(\mathrm{RSP})]$.
} 
Seguiram-se os vários planos de acção plurianual ${ }^{15}$, elaborados pelo Conselho, em cooperação com a Comissão e o Parlamento Europeu, sendo que actualmente está em vigor o plano aprovado para o período de 2019-2023 ${ }^{16}$. A justiça electrónica tem sido uma prioridade, em particular no que respeita à partilha de informação, à e-evidence e, ainda, no desenvolvimento e manutenção da plataforma $e$-codex como um mecanismo comum para o intercâmbio transfronteiriço de informações protegidas padronizadas entre os EstadosMembros em processos judiciais. Está previsto, por exemplo: i) desenvolver novas funcionalidades para o Portal Europeu da Justiça, tais como uma ferramenta de pesquisa central; ii) alargar o âmbito de aplicação das funcionalidades dinâmicas do Portal; iii) criar um assistente para ações de pequeno montante; enriquecer o conteúdo estático do Portal; iv) definir o papel que a inteligência artificial poderá desempenhar no domínio da justiça; v) desenvolver uma ferramenta de inteligência artificial para analisar as decisões dos tribunais; vi) desenvolver um «chatbot» que assista o utilizador e o conduza às informações que procura; vii) partilhar informações, boas práticas e tecnologias que permitam a realização de videoconferência transfronteiras; viii) criar uma ponte//ligação técnica entre os sistemas de resolução de litígios em linha e o procedimento eletrónico da União Europeia para ações de pequeno montante, quando o litígio não é resolvido em linha.

\section{Enquadramento legal}

A criação e implementação de um sistema de justiça electrónica não se encontra no âmbito das competências exclusivas da União, ou seja, trata-se de matéria de competência partilhada entre a União Europeia e os Estados-Membros. Assim sendo, nos domínios que não sejam das suas atribuições exclusivas, a União Europeia apenas pode adoptar medidas que respeitem os princípios da subsidiariedade e da proporcionalidade, os quais regem o exercício das competências da União Europeia e estão consagrados no art. 5. $^{\circ}$, n. $^{\circ}$ 3, do Tratado da União Europeia (TUE) e no Protocolo (n. ${ }^{\circ}$ 2) relativo à sua aplicação. O princípio da subsidiariedade legitima a intervenção da União desde que os objectivos de uma acção não possam ser

\footnotetext{
${ }^{15}$ Consultar: Plano de Acção Plurianual 2009-2013 sobre Justiça Electrónica Europeia (JO C 75 de 31.3.2009); Projecto de Estratégia Europeia de Justiça Electrónica para 2014-2018 (JO C 376 de 21.12.2013); Plano de Acção Plurianual 2014-2018 sobre Justiça Electrónica Europeia (JO C 182 de 14.6.2014). Sobre o caminho percorrido e a percorrer na e-justice, ver QUELHAS, F. F., Justiça Eletrónica Europeia - Finding the Way Forward, em "A Transformação Digital da Justiça”, Direcção Geral da Política da Justiça, 2017, pp. 10-15.

${ }^{16}$ Ver Plano de ação para a justiça eletrónica europeia para 2019-2023, JO C 96 de 13.03.2019.
} 
suficientemente alcançados pelos Estados-Membros, podendo ser melhor alcançados a nível da União, «devido às dimensões ou aos efeitos da acção considerada».

Sem prejuízo desse pressuposto, a Política Europeia em que pode ser enquadrada esta questão da justiça electrónica, é a da criação do espaço de liberdade, segurança e justiça [art. 26. ${ }^{\circ}, 74 .^{\circ}$ e $170 .^{\circ}$ do Tratado sobre o Funcionamento da União Europeia (TFUE) ${ }^{17}$ ] porquanto seria um contributo para o bom funcionamento do mercado único através de mais uma forma de combate às fronteiras jurídicas.

Apesar da possibilidade, dentro dos referidos limites, de a União Europeia adoptar medidas legislativas de criação e aplicação da justiça electrónica, até à data, tudo o que se fez foi com base em soft law, com a aprovação de resoluções e planos de acção, e dirigido apenas ao âmbito transfronteiras. Não obstante, os resultados têm sido muito satisfatórios, o grau de desenvolvimento e aprofundamento das medidas progride com resultados notórios, havendo um claro compromisso dos Estados-Membros na prossecução dos objectivos, numa postura de cooperação recíproca nesta matéria imprescindível para o bom funcionamento da Justiça.

$\mathrm{Na}$ perspectiva do cidadão, a justiça electrónica pode ser encarada como um direito fundamental, ao qual os Estados, internamente, e a União Europeia, supra Estados, devem dar cumprimento, de modo a que o acesso à justiça seja cabalmente concretizado (cfr. art $6 .^{\circ}$ da Convenção Europeia dos Direitos do Homem). Se há alguns anos a existência e efectiva concretização dos sistemas e tecnologias de informação na justiça era apenas uma medida recomendável aos Estados, os quais geriam essa política sem responsabilidades vinculadas,

\footnotetext{
${ }^{17}$ Artigo 26. ${ }^{\circ}$ - 1. A União adopta as medidas destinadas a estabelecer o mercado interno ou a assegurar o seu funcionamento, em conformidade com as disposições pertinentes dos Tratados. 2. O mercado interno compreende um espaço sem fronteiras internas no qual a livre circulação das mercadorias, das pessoas, dos serviços e dos capitais é assegurada de acordo com as disposições dos Tratados. 3. O Conselho, sob proposta da Comissão, definirá as orientações e condições necessárias para assegurar um progresso equilibrado no conjunto dos sectores abrangidos.

Artigo 74. ${ }^{\circ}$ - O Conselho adopta medidas destinadas a assegurar a cooperação administrativa entre os serviços competentes dos Estados-Membros nos domínios abrangidos pelo presente título, bem como entre esses serviços e a Comissão. O Conselho delibera sob proposta da Comissão, sob reserva do artigo $76 .^{\circ}$, e após consulta ao Parlamento Europeu.

Artigo 170. ${ }^{\circ}$ - 1 . A fim de contribuir para a realização dos objectivos enunciados nos artigos $26 .^{\circ}$ e $174 .^{\circ}$ e de permitir que os cidadãos da União, os operadores económicos e as colectividades regionais e locais beneficiem plenamente das vantagens decorrentes da criação de um espaço sem fronteiras internas, a União contribuirá para a criação e o desenvolvimento de redes transeuropeias nos sectores das infra-estruturas dos transportes, das telecomunicações e da energia. No âmbito de um sistema de mercados abertos e concorrenciais, a acção da União terá por objectivo fomentar a interconexão e a interoperabilidade das redes nacionais, bem como o acesso a essas redes. Terá em conta, em especial, a necessidade de ligar as regiões insulares, sem litoral e periféricas às regiões centrais da União.
} 
actualmente podemos estar num processo de evolução, com a elevação do direito à justiça electrónica (ou de algumas das suas facetas) à categoria de direito fundamental.

Sucede, aliás, que o Tribunal Europeu dos Direitos do Homem já foi chamado a pronunciar-se sobre esta matéria, no Processo Lawyer Partners A.S. v. Slovakia, de 16 de junho de $2009^{18}$. No caso concreto, o Tribunal decidiu, com fundamento na violação do art. 6. ${ }^{\circ} .1$ da Convenção, condenar o Estado Eslovaco a indemnizar a empresa requerente num processo que correu termos num tribunal daquele Estado, porquanto lhe foi negado apresentar a petição inicial em suporte electrónico (no caso em DVD), sendo que no caso estava a ser apresentado um elevado número de processos iguais e cuja demanda implicava um articulado extenso e com muitos documentos anexos. Tudo, ascendia a milhares de páginas. Não obstante e apesar de o direito processual interno prever a prática do acto por via electrónica, o Tribunal não recebeu e não registou as petições iniciais, com fundamento na falta de meios técnicos de suporte. No fim, como se disse, o Tribunal Europeu dos Direitos do Homem deu razão à Autora, lesada em consequência da violação do direito de acesso à justiça, que lhe foi negado pelos tribunais do Estado Esloveno.

Apesar dos contornos específicos do caso, é evidente o sinal de que o direito de acesso à justiça tem no seu conteúdo a amplitude que a evolução dos tempos exige. Os Estados, na administração da justiça e na organização da arquitectura judicial, estão obrigados a proporcionar o acesso aos tribunais e a concretização do direito à acção acolhe, também, o direito de usar os meios que de modo mais célere, mais eficaz e menos oneroso proporcione a prática do acto de propositura da acção. Nesse contexto, o uso dos meios electrónicos são o instrumento que começa a tornar-se imprescindível na prossecução dessa função essencial do Estado, que é a Justiça.

\section{3. Âmbito e áreas de actuação}

A justiça electrónica tem aplicação em diferentes âmbitos, seja em razão do espaço, seja em razão da matéria. Quer num, quer noutros, a sua aplicação desdobra-se em várias vertentes.

No âmbito espacial, existe a utilização dos meios electrónicos no ordenamento interno de cada Estado-Membro, sustentado nos sistemas informáticos de cada um, como sucede por exemplo em Portugal com a plataforma CITIUS que suporta a tramitação electrónica dos

\footnotetext{
${ }^{18}$ Consultar em: https://www.legal-tools.org/doc/7bd6ef/pdf/ .
} 
processos judiciais cíveis, assim como existe a aplicação dos meios electrónicos ao nível dos litígios transfronteiriços, onde a referência espacial é o espaço europeu de justiça.

No que concerne à matéria, a justiça electrónica está presente no âmbito dos litígios de natureza cível e é também instrumental em matéria de natureza penal, para além de interligar serviços administrativos.

Relativamente às vertentes de aplicação, há três sectores fundamentais, nos quais se inserem várias medidas e ferramentas criadas na prossecução dos objectivos da justiça electrónica, das quais enunciaremos algumas:

\section{i) Acesso às informações no domínio da justiça}

Uma das medidas prioritárias foi a criação de uma ferramenta de acesso à informação no domínio da justiça, que fosse disponível e de acesso fácil aos cidadãos, através da qual se facultasse a informação num ponto de acesso único, multilingue e convivial a todo o sistema europeu de justiça electrónica, ou seja, a sítios e/ou serviços informativos europeus e nacionais. O Portal Europeu da Justiça ${ }^{19}$, lançado em 16 de julho de 2010, cumpre essa função.

Desde essa data que este sítio na internet apoia cidadãos, empresas, profissionais do direito e magistrados, a quem presta informações, na sua própria língua, sobre os procedimentos europeus e nacionais e o funcionamento da justiça, numa espécie de «balcão único» europeu.

O Portal está constantemente em desenvolvimento, com mais informação e novas funcionalidades, sendo que a mais recente e inovadora é a disponibilização de formulários electrónicos interactivos, em especial nos procedimentos de segunda geração ${ }^{20}$. Por outro lado, a acessibilidade às fontes jurídicas com interfuncionamento semântico é relevante e é já uma realidade.

Há ainda a intenção de facilitar a localização e a citação inequívoca de sentenças e acórdãos dos tribunais europeus e nacionais. Para isso, foi criado o identificador europeu da jurisprudência (ECLI), já em prática por vários Estados-Membros ${ }^{21}$. Este motor de busca está

\footnotetext{
${ }^{19}$ Acessível em https://e-justice.europa.eu/home.do.

${ }^{20}$ Consultar, por exemplo, https://e-justice.europa.eu/content small claims forms-177-pt.do.

${ }^{21}$ No caso português, ver https://jurisprudencia.csm.org.pt/.
} 
também acessível no Portal da Justiça ${ }^{22}$ e permite a pesquisa de decisões dos tribunais de vários Estados.

Também ao nível da partilha de informação, está a ser implementado o projecto Identificador Europeu da Legislação ${ }^{23}$ (ELI) com vista a tornar a legislação disponível em linha num formato normalizado, para que possa ser consultada, intercambiada e reutilizada no espaço europeu. Isso facilita o acesso e conhecimento da legislação, reciprocamente. Esta medida surgiu nas Conclusões do Conselho de 22 de dezembro de $2012^{24}$, e foi desenvolvida nas Conclusões do Conselho, de 6 de novembro de $2017^{25}$.

A preocupação com a atenuação da barreira linguística determinou a criação de portais com sistema de tradução automática, como é o exemplo do EUROVOC ${ }^{26}$ e do IATE ${ }^{27}$.

A agregação da informação numa versão multilinguística, a partilha do regime jurídico do processo e dos procedimentos nos vários Estados-Membros, assim como a disponibilização de formulários, compõem um serviço prestado ao cidadão e aos profissionais forenses que efectivamente contribui para a consolidação do espaço europeu de justiça.

\section{ii) Desmaterialização dos procedimentos}

A desmaterialização dos procedimentos é um instrumento relevante na concretização do direito de acesso aos tribunais, em especial nos procedimentos extrajudiciais em situações transfronteiriças. Neste contexto, foi propósito da União Europeia - hoje já em estado avançado - automatizar o procedimento europeu de injunção de pagamento e o processo europeu para acções de pequeno montante. Os formulários de preenchimento interactivos já podem ser descarregados no e-portal e enviados por via electrónica. Seguir-se-á a criação de condições para o preenchimento on-line e a remessa directamente para o tribunal competente, o que assenta e está dependente da interoperabilidade dos sistemas judiciários, cujo desenvolvimento está sustentado no projecto $e$ - $\operatorname{codex}^{28}$, actualmente em fase de implementação e

\footnotetext{
${ }^{22} \mathrm{Cfr}$. https://e-justice.europa.eu/content_ecli_search_engine-430-pt.do.

${ }^{23}$ Para informação sobre o ELI em Portugal, consultar https://dre.pt/identificador-europeu-legislacao.

24 JO C 325, de 26.10.2012.

25 JO C 441, de 22.12.2017.

${ }^{26} \mathrm{Cfr}$. http://eurovoc.europa.eu/drupal/?q=pt.

${ }^{27}$ Interactive Terminology for Europe Translation, disponível em: http://iate.europa.eu/switchLang.do?success=mainPage\&lang=pt

${ }^{28}$ https://www.e-codex.eu/.
} 
desenvolvimento. Está ainda projectada, como hipótese futura, a criação de sistemas de pagamento em linha das despesas processuais.

Também os mecanismos de resolução extrajudicial de litígios, em especial os de consumo, foram contemplados com a desmaterialização, tendo sido criada uma plataforma de âmbito europeu, para litígios transfronteiriços, que auxilia os consumidores na apresentação de queixas contra empresas, em conflitos de consumo, sendo que a sua resolução é tramitada em linha. Existe a possibilidade de desencadear o procedimento e fazer intervir uma entidade de resolução do litígio (por exemplo, um centro de mediação e arbitragem) através da plataforma $\mathrm{ODR}^{29}$ (on line dispute resolution). A resolução de litígios em linha é um instrumento acessível, informal e célere que capacita as partes na auto-composição dos litígios.

\section{iii) Comunicações entre autoridades judiciárias}

Neste domínio, enquadram-se as comunicações entre serviços e autoridades que lidam e têm a seu cargo a gestão de dados ou perante as quais são realizadas diligências processuais, designadamente com vista à partilha de dados e registos. O referido projecto CODEX electrónico é a base técnica e organizativa que permitirá o intercâmbio seguro de dados jurídicos entre o aparelho judicial, os organismos estatais, os profissionais da justiça, os cidadãos e as empresas. Estão em curso, em alguns casos em fase de implementação e noutros ainda em fase de estudo de viabilidade, a interligação de diferentes tipos de registos, tais como: insolvências, cadastros prediais, registos comerciais, registos de testamentos (certificado sucessório europeu em formato electrónico), de peritos judiciários, bases de dados de intérpretes e tradutores, assim como de mediadores. A disponibilização destes dados em plataformas únicas e acessíveis diminuirá as barreiras da informação, proporcionará ganhos de tempo e diminuição de custos na gestão dos litígios.

Como formas de comunicação entre autoridades judiciárias, o projecto mais emblemático tem sido o da implementação da videoconferência transfronteira, facilitando a audição de testemunhas ou das partes além-fronteiras, assim como de peritos, a fim de acelerar os processos judiciais. Em 2015, são publicadas as Recomendações do Conselho para «Promover a utilização e a partilha de boas práticas sobre a videoconferência transfronteiras no domínio

\footnotetext{
${ }^{29}$ https://ec.europa.eu/consumers/odr/main/?event=main.home2.show.
} 
da justiça nos Estados-Membros e a nível da UE» ${ }^{30}$, dando seguimento ao trabalho feito no âmbito dos planos de acção da justiça electrónica. A União Europeia tem disseminado informação e incentiva a utilização destes meios. Em matéria civil, a base jurídica para requerer a videoconferência pode ser o Regulamento 1206/2001, de 28 de Maio de 2001, relativo à cooperação entre os tribunais dos Estados-Membros no domínio da obtenção de provas em matéria civil ou comercial, conhecido por Regulamento Obtenção de Provas 2001; assim como o art. 9. ${ }^{\circ}$, n. ${ }^{\circ} 1$, do Regulamento 861/2007, de 11 de Julho de 2007, que estabelece um processo europeu para acções de pequeno montante, no qual se prevê a produção de prova através de videoconferência se estiverem disponíveis os meios técnicos necessários. Também a Directiva 2008/52/CE, de 21 de maio de 2008, relativa a certos aspectos da mediação em matéria civil e comercial sublinha que não deverá obstar de modo algum à utilização das modernas tecnologias da comunicação no processo de mediação.

\section{Desafios da justiça electrónica num contexto de diversidade jurídico-cultural}

Todas as medidas, já executadas e em curso, revelam uma justiça moderna, célere, partilhada, assente na cooperação entre Estados, num cenário de efectiva construção de uma espaço de justiça global e ao serviço do cidadão europeu, capaz de nos fazer sentir beneficiários de um verdadeiro serviço público europeu. A Justiça fará o seu caminho além-fronteiras e os Estados-Membros serão capazes de aprofundar as relações de cooperação judiciária, criando mais e melhores meios que incentivem a utilização e aplicação de boas práticas na justiça, onde os sistemas de informação tenham um papel instrumental bem presente mas, sobretudo, eficaz.

Em todo o caso, ainda que o contexto pareça integralmente favorável, a verdade é que existem ainda algumas barreiras a atenuar. A questão semântica é um elemento a ter em atenção. Porquanto, a diversidade de ordenamentos jurídicos internos e a respectiva terminologia técnico-jurídica impede a identidade de conceitos cuja tradução nem sempre é fiel.

Não se pode descurar, por outro lado, a monitorização e actualização da informação disponibilizada no Portal Europeu. As constantes alterações legislativas nos ordenamentos internos podem dificultar a tarefa de manter coerentes e actuais os conteúdos relacionados com os regimes jurídicos internos.

${ }^{30}$ JO C 250, de 31.7.2015. 


\section{Relações de consumo e litígios transfronteiriços - as TIC como instrumento de eficácia e celeridade}

As questões em que nos vamos deter dizem respeito à utilização das TIC nas vertentes de acesso aos tribunais e comunicações entre autoridades, naquilo em que possam suportar o bom andamento dos procedimentos que tutelam os direitos emergentes de relações de consumo, em litígios transfronteiriços.

\section{Protecção das relações de consumo na União Europeia}

As relações de consumo têm sido uma área de referência e de atenção por parte das instituições europeias. Facilmente se compreende que os consumidores e as empresas suscitem atenção, ainda que por motivos diversos, porquanto representam os principais actores no terreno do mercado único europeu. Os consumidores, enquanto parte frágil na respectiva relação jurídica, devem sentir-se protegidos, de modo a continuarem a incrementar a procura de bens e serviços; as empresas, fornecedoras desses bens e serviços, são peças indispensáveis no desenvolvimento e no sucesso económico do espaço europeu ${ }^{31}$.

Neste sentido, a União Europeia adoptou uma política dos consumidores, considerada como um contributo essencial para a estratégia «Europa 2020». A Comissão Europeia apresentou, em maio de 2012, Uma Agenda do Consumidor Europeu para incentivar a confiança e o crescimento ${ }^{32}$, que também é seguida no programa para a política do consumidor, a vigorar no período 2014-2020. Esta Agenda procurou agregar, com especial incidência nos sectores da alimentação, energia, serviços financeiros, transportes e digital, medidas que visam: reforçar a segurança dos consumidores; aumentar o seu nível de conhecimento, de modo a

\footnotetext{
${ }^{31}$ Como refere a Comissão, na Agenda do Consumidor: “As despesas de consumo representam $56 \%$ do PIB da UE, sendo essenciais para a consecução dos objectivos da estratégia «Europa 2020», a saber um crescimento inteligente, inclusivo e sustentável. O incentivo da procura pode desempenhar um papel fundamental para a saída da UE da crise". Cfr. Comunicação da Comissão ao Parlamento Europeu, ao Conselho, ao Comité Económico e Social Europeu e ao Comité das Regiões, sobre Uma Agenda do Consumidor Europeu para incentivar a confiança e o crescimento, $\operatorname{COM}(2012) 225$ final, de 22.5.2012, p. 1.

32 "Em conformidade com o Tratado (artigo 12. ${ }^{\circ}$ do TFUE) e a Carta dos Direitos Fundamentais (artigo 38..$^{\circ}$ ), a Agenda desenvolve uma abordagem sistemática para a integração dos interesses dos consumidores em todas as políticas pertinentes e confere uma ênfase especial na luta contra os problemas com que se deparam os consumidores de hoje nos sectores da alimentação, da energia, dos transportes, dos produtos e serviços digitais e dos serviços financeiros. Consolida o elevado nível de protecção dos consumidores, já alcançado, e os progressos realizados na criação de um espaço europeu de justiça, potenciando o papel que os juízes, os profissionais da justiça e as autoridades responsáveis pela aplicação da lei podem desempenhar, nomeadamente além-fronteiras", ibidem, p. 2.
} 
capacitá-los com informação e meios de recurso perante mercados mais complexos; melhorar as práticas de fiscalização e controlo dos mercados, promovendo uma maior cooperação entre as diferentes redes administrativas; alinhar a política de defesa do consumidor com as mudanças na sociedade, tornando-a relevante na vida diária. Mais recentemente, em finais de 2020, foi aprovada a Nova Agenda do Consumidor - Reforçar a resiliência dos consumidores para uma recuperação sustentável ${ }^{33}(2020-2025)$ que assenta em cinco áreas prioritárias: i) a transição verde; ii) a transformação digital; iii) medidas de reparação e enforcement dos direitos do consumidor; iv) necessidades específicas de certos grupos de consumidores; e, v) cooperação internacional.

No que nos importa realçar, tem sido assinalado, como expresso propósito: «melhorar a aplicação da legislação, reforçar as medidas de execução e garantir os meios de acção». Concretamente no direito de acção, a União Europeia comprometeu-se a assegurar aos consumidores um acesso mais fácil ao procedimento europeu para as acções de pequeno montante, na medida em que simplifica acelera e reduz os custos dos processos judiciais em casos além-fronteiras para os pedidos de indemnização, embora com limite de valor, cujo limiar já se propunha aumentar, assim como já anunciava que pretendia colocar em linha os formulários relativo às acções de pequeno montante e informar sobre a tramitação do procedimento no seu conjunto ${ }^{34}$.

\section{Relações de consumo e litígios transfronteiriços}

É já indiscutível que o espaço de consumo não é nacional, é global, e não é apenas físico, mas também digital. A globalização e a digitalização, como oportunamente se apontou, foram fenómenos que alteraram por completo o figurino de todas as relações interpessoais, sejam jurídicas, económicas ou mesmo pessoais. É neste novo mundo que as pessoas actuam. É a este novo mundo que nos temos que adaptar.

Os litígios de consumo assumiram uma dimensão diferente e são, cada vez mais, litígios com elementos de conexão que assumem contacto com vários Estados e com várias ordens jurisdicionais. Frequentemente se encontrará um litígio emergente de uma relação de consumo em que, pelo menos, um destes elementos não coincidirá no mesmo Estado-Membro: a

\footnotetext{
${ }^{33} \operatorname{COM}(2020) 696$ final, Bruxelas, 13.11.2020.

${ }^{34}$ Ibidem, p. 12.
} 
nacionalidade do consumidor, o domicílio do consumidor, a sede da empresa, o lugar da celebração do contrato, o lugar do cumprimento. Os litígios transfronteiriços ou além-fronteiras ganham claramente espaço na litigiosidade do consumo. E os casos abundam, como se pode exemplificar:

i. A empresa de tecnologias de informação XPTO, com sede no Luxemburgo, vendeu a Jaume, francês com domicílio em Bruxelas, um software que desenvolveu para jogos. O preço foi fraccionado, mas o cliente pagou apenas a primeira prestação e não cumpriu as interpelações para pagamento, pelo que parte do preço se encontra em dívida.

ii. Marie, de nacionalidade belga, com domicílio em Paris, fez um pedido on-line para uma empresa alemã de mobiliário, tendo pago antecipadamente o preço. Recebida a mercadoria, constatou que algum material estava partido. Contactou a empresa, mas o serviço de apoio ao cliente, por correspondência, recusa-se a substituir o bem ou a reembolsar os custos.

iii. Ana, portuguesa, com domicílio em Madrid, encomendou uma máquina fotográfica num site austríaco e pagou antecipadamente $€ 1.500$, por transferência bancária. $\mathrm{O}$ comerciante não entregou a máquina e não reembolsa o preço de compra.

Estes exemplos demonstram os vários tipos de litígios que podem surgir. Como se vê, podem estar em causa demandas em que é o consumidor lesado que pretende peticionar a entrega do bem e, eventualmente, uma indemnização por danos causados; outros em que poderá vir a pedir a substituição ou a reparação do bem; outros, ainda, em que é a empresa que visa a cobrança do preço ou de parte dele.

Foi para eventuais litígios desta natureza, em que ocorrem situações de incumprimento ou de cumprimento defeituoso, designadamente nas relações de consumo, que a União Europeia criou procedimentos europeus aos quais quer as empresas, quer os consumidores, podem recorrer na defesa dos seus direitos.

\section{Os procedimentos europeus de segunda geração aplicáveis aos litígios de consumo} transfronteiriços

Os procedimentos europeus que, enquanto mecanismos de carácter subsidiário face aos procedimentos ou processos internos, estão ao serviço dos litígios de consumo transfronteiriços 
são: o procedimento europeu de injunção de pagamento ${ }^{35}$ e o processo europeu para acções de pequeno montante ${ }^{36}$. O primeiro, especialmente destinado à cobrança de dívidas pecuniárias, será um instrumento usado pelas empresas para exigir o pagamento do preço; o segundo, na medida em que o seu objecto não se restringe a exigir o cumprimento de obrigações pecuniárias, será o meio mais adequado às pretensões do consumidor.

São designados de procedimentos europeus de segunda geração na medida em que foram criados por instrumentos europeus de aplicação directa nos ordenamentos dos EstadosMembros com a prerrogativa de consagrarem mecanismos onde a decisão proferida é imediatamente executória nos outros Estados que não o Estado de origem, o que determinou um progresso no Direito Processual Civil Europeu.

\section{i) Procedimento europeu de injunção de pagamento}

A injunção europeia veio introduzir um mecanismo idêntico àquele que é vigente em muitos Estados-Membros e através do qual se pretende facilitar a obtenção de um título executivo, neste caso com força executória transfronteiriça, na sequência da interpelação do devedor para o pagamento de uma dívida de origem contratual, dando-lhe oportunidade de deduzir oposição ao requerimento, situação em que o procedimento de injunção se converterá numa acção declarativa para efeitos de conhecimento da existência do crédito.

Assim, o titular de um crédito pecuniário relativo a matéria civil e comercial (no sentido que lhe é dado pelo art. 2. ${ }^{\circ}$, do Regulamento 1896/2006) pode usar da injunção de pagamento europeia, desde que o litígio seja transfronteiriço, na expectativa de obter mais rapidamente um título executivo que circule no espaço europeu sem necessidade de mais nenhum procedimento adicional. Para o efeito, apresentará, nos termos do art. 7. $^{\circ}$, requerimento próprio - com recurso aos formulários - que será analisado pelo tribunal ${ }^{37}$ a fim de verificar a conformidade do requerimento com todos os requisitos estabelecidos nos arts. $2 .^{\circ}, 3 .^{\circ}, 4 .^{\circ}, 6^{\circ}$ e $7 .^{\circ}$, do citado Regulamento. Feita a análise do requerimento, o tribunal recusa, nos termos e com os fundamentos indicados no art. $11 .^{\circ}$, ou recebe o requerimento, se todos os pressupostos se verificarem. Se for este o caso, emitirá a injunção de pagamento europeia, juntamente com

\footnotetext{
${ }^{35}$ Criado pelo Regulamento 1896/2006 do Parlamento Europeu e do Conselho, de 12 de Dezembro de 2006.

${ }^{36}$ Aprovado pelo Regulamento 861/2007 do Parlamento Europeu e do Conselho, de 11 de Julho de 2007.

${ }^{37}$ Por «Tribunal» entende-se qualquer autoridade de um Estado-Membro competente em matéria de injunções de pagamento europeias ou em quaisquer outras matérias conexas (art. 5. ${ }^{\circ}$, n. ${ }^{\text {o }}$ 3, do Regulamento 1896/2006).
} 
uma cópia do formulário de requerimento. Dessa injunção é citado ou notificado o requerido, nos termos da lei do Estado em que tal citação ou notificação deva ser feita e de acordo com as modalidades previstas nos arts. $13 .^{\circ}$ e $14 .^{\circ}$, do Regulamento 1896/2006, para:

- Pagar ao requerente o montante indicado na injunção; ou

- Deduzir oposição à injunção de pagamento mediante a apresentação de uma declaração de oposição, no prazo de 30 dias a contar da citação ou notificação.

Nessa comunicação, o requerido é advertido de que a injunção de pagamento adquirirá força executiva se não for apresentada uma declaração de oposição, nos termos do art. $16 .^{\circ}$, ou de que a acção prosseguirá nos tribunais competentes do Estado-Membro de origem se for apresentada oposição ao requerimento, sendo que o processo a seguir será o processo europeu para acções de pequeno montante, se aplicável, ou o processo que tenha lugar face às normas processuais internas (art. 17. ${ }^{\circ}$, do Regulamento1896/2006, na versão que lhe foi dada pelo Regulamento 2015/2421, de 16 de dezembro de 2015, em vigor desde 14 de Julho de 2017). Pode suceder, caso o requerente o haja solicitado, que se ponha termo ao processo em caso de oposição.

Assim, após a citação ou notificação do requerido, se este não apresentar oposição será imediatamente declarada executória a injunção de pagamento europeia, através de emissão do respectivo formulário que será enviado ao requerente, ficando este munido de um «título executivo europeu», se atendermos a este conceito como sendo um título executivo com força executória no espaço europeu (cfr. art. 18. ${ }^{\circ}$, do Regulamento1896/2006).

Este foi um dos primeiros casos de abolição do exequatur, porquanto no fim de um único procedimento o credor consegue, sem mais, beneficiar dos efeitos de reconhecimento e execução transfronteiriça da declaração de injunção de pagamento europeia. De acordo com o art. 19. ${ }^{\circ}$, a injunção de pagamento europeia que tenha adquirido força executiva no EstadoMembro de origem é reconhecida e executada nos outros Estados-Membros sem que seja necessária uma declaração de executoriedade e sem que seja possível contestar o seu reconhecimento.

\section{ii) Processo europeu para acções de pequeno montante}

Este procedimento configura, processualmente, uma verdadeira acção declarativa, de origem comunitária, destinado a simplificar e a acelerar as acções de pequeno montante em 
casos transfronteiriços - isto é, aqueles em que pelo menos uma das partes tenha domicílio ou residência habitual num Estado-Membro que não seja o Estado-Membro do órgão jurisdicional a que o caso é submetido - e reduzir as respectivas despesas, o qual constitui uma alternativa aos processos existentes nos termos da lei dos Estados-Membros com a vantagem de obter uma decisão cujos efeitos executórios se repercutem no espaço europeu de justiça.

A criação deste procedimento visou melhorar o acesso à justiça tanto para as empresas como para os consumidores, através de menores custos e mais celeridade processual em casos transfronteiriços, contribuindo para a tutela efectiva dos direitos.

A acção europeia de pequeno montante tem por objecto litígios de natureza civil ou comercial, independentemente da natureza do órgão jurisdicional, contestados ou não contestados, em que o valor do pedido não exceda 5.000 euros no momento em que o formulário de requerimento é recebido no órgão jurisdicional competente, excluindo todos os juros, custos e outras despesas. Estão abrangidas obrigações pecuniárias ou não pecuniárias, de origem contratual ou extracontratual, em matéria civil e comercial. Ficam excluídos casos de natureza fiscal, aduaneira e administrativa, assim como a responsabilidade do Estado por actos e omissões no exercício do poder público (acta jure imperii). Estão igualmente afastadas: a) as questões relacionadas com o estado ou a capacidade das pessoas singulares; b) os direitos patrimoniais decorrentes de regimes matrimoniais, de obrigações de alimentos, de testamentos e de sucessões; c) as falências e as concordatas em matéria de falência de sociedades ou outras pessoas colectivas, os acordos de credores ou outros procedimentos análogos; d) a segurança social; e) a arbitragem; f) o direito do trabalho; g) o arrendamento de imóveis, excepto em acções pecuniárias; ou h) as violações da vida privada e dos direitos da personalidade, incluindo a difamação (art. 2. ${ }^{\circ}$ do Regulamento 861/2007).

O processo europeu para acções de pequeno montante também se inicia com um requerimento em formulário próprio, apresentado pelo requerente ao órgão jurisdicional competente, que será aferido de acordo com as regras previstas no Regulamento Bruxelas I (art. 4. ${ }^{\circ}$ do Regulamento 861/2007). Havendo de ser recebido o requerimento, abre-se um processo declarativo com cumprimento do contraditório e caracterizado por ser um processo escrito $^{38}$, pois embora esteja prevista a realização de uma audiência, esta só será realizada se o

\footnotetext{
${ }^{38} \mathrm{Na}$ verdade, passa a prevalecer a escrita sobre a oralidade, numa opção que parece basear-se mais no facto de se entender tratar-se de um instrumento mais eficaz para evitar os custos associados à oralidade nos casos transfronteiriços e, consequentemente, promover o acesso à justiça, do que, propriamente, nas vantagens dessa
} 
tribunal a considerar necessária ou se uma das partes o requerer. Ainda assim, mesmo neste caso, pode esse pedido ser indeferido se se concluir que a audiência é claramente desnecessária para assegurar um processo equitativo (art. $5^{\circ}$, n. $^{\circ} 1$, do referido Regulamento). Recebida a resposta do requerido - ou a do requerente, no caso de haver pedido reconvencional - o órgão jurisdicional, se não houver de solicitar esclarecimentos suplementares, de solicitar a produção de prova ou de notificar as partes para comparecerem numa audiência, profere logo decisão no prazo de 30 dias, o que igualmente sucederá, conforme os casos, após a recepção dos esclarecimentos, da produção de prova ou da realização da audiência, como dispõe o art. 7. , do Regulamento 861/2007.

Como se disse, as decisões proferidas num Estado-Membro em processo europeu para acções de pequeno montante são reconhecidas e executadas nos outros Estados-Membros sem necessidade de declaração de executoriedade e sem que seja possível contestar o seu reconhecimento (art. 20. ${ }^{\circ}$ n. $^{\circ}$ 1, do Regulamento 861/2007). A execução que venha a ter lugar no Estado de destino basear-se-á na cópia da decisão e em certidão relativa à decisão proferida em processo europeu para acções de pequeno montante, emitida a requerimento de uma das partes e segundo o modelo D constante do anexo IV (cfr. arts. $20 .^{\circ}$ e $21 .^{\circ}$, do Regulamento). Essa certidão contém os elementos essenciais da decisão (identificação das partes, do órgão jurisdicional e resumo da decisão, com os dados essenciais da decisão, designadamente o valor em que o requerido vai condenado) e nela se faz uma declaração sobre o reconhecimento e carácter executório da mesma, reiterando-se que esses efeitos se produzem sem necessidade de declaração de executoriedade e sem que seja possível contestar o seu reconhecimento.

\section{Mecanismos procedimentais e e-justice}

A sustentabilidade dos procedimentos de segunda geração passa pela sua maior acessibilidade, informalidade e celeridade. Entre os instrumentos que auxiliam essa tarefa encontramos o suporte electrónico dos formulários, assim como das notificações e comunicações. Neste contexto, as mais recentes alterações aprovadas pelo Regulamento 2015/2421, demonstram o empenho do legislador na construção de processos, tanto quanto

metodologia processual. Cfr. GASCÓN INCHAUSTI, F., Algunas reflexiones acerca de la oralidad y la prueba en el processo europeo de escasa cuantía, AEDIPr, t. VI, 2006, pp. 285 e ss., em especial, pp. 292 e ss. O autor alerta, no entanto, para as repercussões que esta opção pode ter ao nível da deficiente formação da convicção do juiz. 
possível, desmaterializados e apoiados nos sistemas de informação, incentivando a sua utilização pelas partes e pelos órgãos jurisdicionais.

Particularmente nas small claims, houve intenção de criar soluções que pudessem contribuir para esbater a distância geográfica e, reflexamente, os custos elevados e a morosidade processual que dela resultam. E essas soluções foram encontradas tirando partido da evolução tecnológica no domínio da justiça e dos novos instrumentos ao dispor dos órgãos jurisdicionais. Designadamente ${ }^{39}$ :

- Na notificação de documentos às partes, equiparação da notificação electrónica à notificação postal, mediante a definição de um quadro geral que permite a utilização da notificação electrónica sempre que se disponha dos meios técnicos necessários e que a utilização dessa notificação seja compatível com as regras processuais nacionais dos Estados-Membros envolvidos.

- Nas outras comunicações escritas entre as partes ou entre outras pessoas envolvidas no processo e os órgãos jurisdicionais, dar preferência, na medida do possível, aos meios electrónicos, se estiverem disponíveis e forem admissíveis.

- As audiências, embora apenas sejam realizadas a título excepcional, caso não seja possível formar a decisão com base nas provas escritas ou caso um órgão jurisdicional aceite realizar a audiência a pedido de uma das partes, bem como a produção de prova através da audição de testemunhas, peritos ou partes, deverão ser efectuadas utilizando qualquer meio de comunicação à distância apropriado ao dispor do órgão jurisdicional, salvo se, atendendo às circunstâncias particulares do caso, a utilização dessa tecnologia não seja adequada para assegurar um processo equitativo.

- Criar condições para que os órgãos jurisdicionais competentes em matéria de processos europeus para acções de pequeno montante tenham acesso a uma tecnologia de comunicação à distância apropriada, a fim de assegurar um processo equitativo, tendo em conta as circunstâncias particulares do caso.

- No que respeita à utilização da videoconferência, ter em consideração as Recomendações do Conselho sobre videoconferência transfronteiras, de 15 e 16

\footnotetext{
${ }^{39} \mathrm{O}$ resumo das medidas adoptadas tem por base os Considerandos do Regulamento 2015/2421.
} 
de junho de 2015, bem como os trabalhos realizados no quadro da justiça electrónica europeia.

- Proporcionar pelo menos um dos métodos de pagamento à distância, de modo a evitar que para o pagamento das custas processuais o requerente tenha de se deslocar ao Estado-Membro do órgão jurisdicional a que o caso foi submetido ou de contratar um advogado para o efeito.

- Emissão da certidão para a execução de uma decisão proferida no âmbito do processo europeu para acções de pequeno montante, ou de uma transacção judicial aprovada por um órgão jurisdicional ou celebrada perante um órgão jurisdicional no âmbito desse processo, traduzida por tradutor aplicado ao formulário interactivo da certidão disponível no Portal Europeu da Justiça.

A preocupação em implementar os meios electrónicos é evidente, sem que, apesar disso, seja descurada a segurança e as garantias das partes, assim como o carácter subsidiário das medidas. É também claro o contributo destas medidas para a tutela efectiva e acesso à justiça.

Contudo, a legislação, só por si, não é suficiente para que sejam alcançados os objectivos. Neste caso, mais do que em todos os outros, a existência, ou não, dos meios e da sua implementação, no terreno de actuação dos mecanismos, é fundamental. Sem que os EstadosMembros se empenhem na criação de condições materiais, designadamente com equipamentos dos órgãos jurisdicionais, nada do que se encontra previsto terá, na verdade, os resultados perspectivados. Ao que acresce, ainda, a necessidade de a legislação interna se adaptar e criar as condições legais que permitam a aplicação efectiva do regime, porquanto as exigências do princípio da subsidiariedade fazem sempre prevalecer a lei processual interna.

Em jeito de balanço dos aspectos positivos, sem dúvida que a vertente tecnológica aplicada aos procedimentos de segunda geração irá facilitar o acesso, diminuir tempo e custos. Essa nova realidade pode capacitar as partes e motivá-las no exercício do seu direito de acção através dos processos europeus.

\section{Avaliação da utilização dos procedimentos europeus no espaço europeu de justiça}

Em 2017, foram publicados dois estudos: “An evaluation study of national procedural laws and practices in terms of their impact on the free circulation of judgments and on the 
equivalence and effectiveness of the procedural protection of consumers under EU consumer law: Strand 1 - Mutual Trust and Free Circulation of Judgments; Strand 2 - Procedural Protection of Consumers ${ }^{40 "}$, ambos relacionados com a matéria do consumo e da defesa do consumidor, com vista à proposta de medidas de melhoria do quadro legal europeu nessa matéria, assim como da eficácia dos procedimentos.

O primeiro relatório analisou o modo como a legislação e as práticas processuais nacionais têm contribuído para a livre circulação e reconhecimento das decisões, assim como para a eficácia da protecção dos consumidores, designadamente no acesso à justiça, ao abrigo da legislação da União Europeia em matéria de consumo. Em especial, o impacto do título executivo europeu, da injunção europeia e do processo europeu para acções de pequeno montante.

Alguns dos pontos assinalados no estudo levam a concluir que há caminho feito mas, também, que há ainda muito caminho a fazer, e nesse percurso há contributos que não são controláveis pelos Estados, que dependem de comportamentos, de vontades, e uns e outros têm que ser motivados e influenciados por factores que credibilizem os procedimentos transfronteiriços e os tornem um porto seguro e de alcance fácil, designadamente para os consumidores.

Vejamos algumas das conclusões:

- Os procedimentos europeus geralmente funcionam bem dentro das ordens jurídicas nacionais, apesar dos diferentes modos de implementação. Porém, na prática nem todos os instrumentos são usados e os profissionais, assim os potenciais usuários não estão muito familiarizados com os instrumentos, em particular no caso da injunção europeia e do das acções de pequeno montante.

- Em vários Estados-Membros, os instrumentos não foram adaptados à legislação nacional, criando incertezas na prática legal. A injunção europeia e as acções de pequeno montante são procedimentos europeus autónomos, mas funcionam dentro do contexto processual nacional e todas as questões processuais que não são resolvidas no Regulamento devem ser tratadas de acordo com o direito processual nacional. Para garantir a eficácia do

\footnotetext{
${ }^{40}$ Report prepared by a Consortium of European Universities (Hess, Requejo Isidro, Gascón Inchausti, Oberhammer, Storskrubb, Cuniberti, Kern, Weitz, Kramer) led by the Max Planck Institute Luxembourg for Procedural Law as commissioned by the European Commission [JUST/2014/RCON/PR/CIVI/0082], Luxembourg: Publications Office of the European Union, 2017.
} 
procedimento, as leis nacionais devem facilitar o bom funcionamento desses instrumentos. Isto inclui a criação de legislação de adaptação e articulação com as normas internas - por exemplo, no Código de Processo Civil ou em actos separados. Tendo em conta que há aspectos internos, como por exemplo o tribunal competente e/ou autoridades, os métodos de comunicação, os requisitos linguísticos e as disposições sobre os custos, que são remetidos para a lei processual interna, há que "incorporar" o procedimento dentro do sistema doméstico.

- O mecanismo de revisão, tal como existe nos termos dos instrumentos, deve ser alinhado e, eventualmente, repensado.

- É necessário, para aplicação dos instrumentos, um sistema de documentos transfronteiriços que funcione bem e de forma eficiente.

- No caso do título executivo europeu, os problemas específicos são menores, na medida em que perderam espaço para a injunção europeia e abolição do exequatur, ao abrigo do Regulamento Bruxelas I-bis, reduziu a importância deste instrumento. No entanto, em alguns Estados-Membros, falta uma legislação de execução adequada, o que cria dificuldades aos profissionais; e, nem todos os procedimentos nacionais dos Estados-Membros parecem estar em conformidade com as regras de revisão incluídas no artigo 19. ${ }^{\circ}$, do Regulamento 805/2004, como aliás sucede com o caso português, apesar de o legislador não o reconhecer.

- A injunção europeia não tem apresentado muitas dificuldades. No entanto, a não aplicação do recurso previsto no artigo $200^{\circ}$ à situação em que a execução do pedido foi concedida, apesar da falta de notificação na pessoa do requerido, caso os requisitos aí previstos não se verifiquem, é pouco garantístico. Pelo menos, deve haver clara e acessível informação sobre as medidas nacionais de reparação disponíveis em tal situação.

- Quanto ao procedimento europeu de acções de pequeno montante, espera-se que o aumento do valor, juntamente com uma série de outras alterações relacionadas com os custos, o pagamento, a língua e a assistência prática, implementada pelo novo regulamento, juntamente com esforços contínuos para aumentar a conscientização e melhorar a aplicação prática, será suficiente para enfrentar os problemas mais importantes.

\section{Conclusões}

Há um novo paradigma da justiça no espaço europeu. E-justice será o ponto de agregação e convergência dos sistemas internos dos Estados-Membros. As comunicações por via electrónica, a partilha de dados em plataformas comuns, a desmaterialização dos processos, a 
interoperabilidade e o acesso directo a tribunais estrangeiros através de plataformas digitais, a cooperação em rede, a partilha de informação e formação, são realidades que emergem e podem, efectivamente, provocar uma evolução no processo civil europeu. Os procedimentos europeus de segunda geração, em especial ao serviço dos litígios transfronteiriços de consumo, estão a ser dotados de instrumentos capazes de proporcionar acessibilidade e celeridade.

Apesar do contexto legislativo e materialmente favorável, os efeitos das medidas já adoptadas no âmbito da e-justice não vão ser imediatos. Como sempre sucede com a implementação das soluções baseadas nos sistemas de informação, não há uma convergência directa e proporcional entre os instrumentos e a sua utilização pois, considerando o comportamento padrão do utilizador, a evolução dá-se a ritmos diferentes. Normalmente, as ferramentas informáticas são criadas e desenvolvem-se a um ritmo muito mais avançado do que o da sua utilização. Existe e é natural no comportamento humano, um estigma em relação ao que é novo e diferente daquilo que são os hábitos instalados e assumidos como seguros, porque são conhecidos e do domínio do utilizador.

Ora, o cidadão europeu não se afasta deste perfil comportamental, os profissionais nacionais também não se pautam por irreverências, todos preferem um meio judicial com o qual se sentem familiarizados, onde dominam os conceitos e os trâmites, pelo que raramente são levados a sair da sua zona de conforto. Acresce, ainda, que as diferentes maturidades jurídicas, assim como os variados níveis de desenvolvimento dos sistemas de informação, vão provocar dificuldades na harmonização e na convergência das soluções e da sua aplicação efectiva nos Estados-Membros.

Espera-se que as recentes alterações nas small claims possam contribuir para a solução dos problemas apontados nos relatórios apresentados, de modo que as próximas avaliações de impacto mostrem uma verdadeira mudança de comportamento das empresas, do cidadão consumidor e, sobretudo, dos profissionais forenses.

Apesar de tudo, a e-justice é um caminho sem retorno. O futuro ditará uma aproximação entre os mecanismos disponíveis e as vontades, num sinal de evolução jurídico-cultural consentâneo com a perspectiva europeia de criação de um verdadeiro espaço europeu de justiça, onde cada cidadão e cada profissional pense e actue para além das suas «fronteiras» jurídicas. 


\section{Referências legislativas e bibliográficas}

BEERGREHN, Ulrika, in "Conselho da União Europeia, Direito Civil, Cooperação Judiciária Europeia". Luxemburgo: Serviço das Publicações Oficiais das Comunidades Europeias, 2005, p. 261-270.

Carta dos Direitos Fundamentais (artigo 38. ${ }^{\circ}$ ).

CARVAlHO, J. M., Manual de Direito do Consumo, 4. a edição, Coimbra: Almedina, 2017, pp. 21-30.

Comunicação da Comissão ao Parlamento Europeu, ao Conselho, ao Comité Económico e Social Europeu e ao Comité das Regiões, sobre Uma Agenda do Consumidor Europeu para incentivar a confiança e o crescimento, $\operatorname{COM}(2012) 225$ final, de 22.5.2012, p. 1.

COUNCIL OF THE EUROPEAN UNION. Brussels, 5 June 2007. Disponível em: http://register.consilium.europa.eu/doc/srv?l=EN\&f=ST\%2010393\%202007\%20INI.

Acesso em: 1 fev. 2018.

Decisão do Conselho de 28 de Maio de 2001 (2001/470/CE), publicada no JO L 174 de 27.6.2001.

Directiva 2008/52/CE do Parlamento Europeu e do Conselho (JO L 136/3, de 24.5.2008).

DRE: DIÁRIO DA REPÚBLICA ELETRÓNICO. Identificador europeu da legislação (ELI).

Disponível em: https://dre.pt/identificador-europeu-legislacao .

E-CODEX MAKING JUSTICE FASTER.EU. Disponível em: https://www.e-codex.eu/.

EUROPEAN COMMISSION [JUST/2014/RCON/PR/CIVI/0082]. An evaluation study of national procedural laws and practices in terms of their impact on the free circulation of judgments and on the equivalence and effectiveness of the procedural protection of consumers under EU consumer law. Luxembourg: Publications Office of the European Union, 2017.

EUROPEAN E-JUSTICE. Acções de pequeno montante - formulários. Disponível em: https://e-justice.europa.eu/content_small_claims_forms-177-pt.do .

EUROPEAN E-JUSTICE. Motor de pesquisa ECLI. Disponível em: https://ejustice.europa.eu/content_ecli_search_engine-430-pt.do .

EUROPEAN PARLIAMENT. "Rebooting” the Mediation Directive: Assessing the limited impact of its implementation and proposing measures to increase the number of 
Revista Eletrônica de Direito Processual - REDP.

Rio de Janeiro. Ano 15. Volume 22. Número 3. Setembro a Dezembro de 2021

Periódico Quadrimestral da Pós-Graduação Stricto Sensu em Direito Processual da UERJ

Patrono: José Carlos Barbosa Moreira (in mem.). ISSN 1982-7636. pp. 656-683

www.redp.uerj.br

mediations in the EU, 2014, disponível em

http://www.europarl.europa.eu/RegData/etudes/etudes/join/2014/493042/IPOL-

JURI_ET(2014)493042_EN.pdf .

EUROVOC. Disponível em: http://eurovoc.europa.eu/drupal/?q=pt.

GASCÓN INCHAUSTI, F., Algunas reflexiones acerca de la oralidad y la prueba en el processo europeo de escasa cuantía, AEDIPr, t. VI, 2006.

IATE EUROPEAN UNION TERMINOLOGY. Interactive Terminology for Europe Translation.

Disponível em: http://iate.europa.eu/switchLang.do?success=mainPage\&lang=pt.

Lei de Defesa do Consumidor, aprovada pela Lei n..$^{\circ}$ 24/96, de 31 de Julho (art. 2. ${ }^{\circ}$, n. ${ }^{\circ}$ ).

Nova Agenda do Consumidor - Reforçar a resiliência dos consumidores para uma recuperação sustentável, 2020-2025, COM(2020) 696 final, Bruxelas, 13.11.2020.

ONLINE DISPUTE RESOLUTION. Disponível em:

https://ec.europa.eu/consumers/odr/main/?event=main.home2.show.

Plano de ação para a justiça eletrónica europeia para 2019-2023, JO C 96 de 13.03.2019.

Plano de Acção de Viena, publicado no JO C 19/1, de 23.01.1999.

Plano de Acção Plurianual 2009-2013 sobre Justiça Electrónica Europeia (JO C 75 de 31.3.2009).

Plano de Acção Plurianual 2014-2018 sobre Justiça Electrónica Europeia (JO C 182 de 14.6.2014).

PONTO DE CONTACTO DE PORTUGAL DA RJE-CIVIL. Rede Nacional de Juízes para apoiar actividade da RJE Civil. Disponível em: https://www.redecivil.csm.org.pt/ .

Processo Lawyer Partners A.S. v. Slovakia, de 16 de junho de 2009. Disponível em: https://www.legal-tools.org/doc/7bd6ef/pdf/ .

Projecto de Estratégia Europeia de Justiça Electrónica para 2014-2018 (JO C 376 de 21.12.2013).

QUELHAS, F. F., Justiça Eletrónica Europeia - Finding the Way Forward, em "A Transformação Digital da Justiça”, Direcção Geral da Política da Justiça, 2017, pp. 1015.

Regulamento 805/2004 do Parlamento Europeu e do Conselho, de 21 de abril de 2004.

Regulamento 1896/2006 do Parlamento Europeu e do Conselho, de 12 de dezembro de 2006. Regulamento 861/2007 do Parlamento Europeu e do Conselho, de 11 de julho de 2007. 
Rio de Janeiro. Ano 15. Volume 22. Número 3. Setembro a Dezembro de 2021

Periódico Quadrimestral da Pós-Graduação Stricto Sensu em Direito Processual da UERJ

Patrono: José Carlos Barbosa Moreira (in mem.). ISSN 1982-7636. pp. 656-683

www.redp.uerj.br

Regulamento 2015/2421 do Parlamento Europeu e do Conselho, de 24 de dezembro de 2015.

Relatório da Comissão ao Conselho, ao Parlamento Europeu e ao Comité Económico e Social Europeu sobre a aplicação da Decisão n. ${ }^{\circ}$ 2001/470/CE do Conselho que cria uma rede judiciária europeia em matéria civil e comercial, SEC (2006) 579 (COM/2006/0203 final de 16.05.2006).

Relatório da Comissão ao Parlamento Europeu, ao Conselho e ao Comité Económico e Social Europeu, sobre a aplicação da Directiva 2008/52 (COM (2016) 542 final, 26.8.2016).

Relatório do Parlamento Europeu sobre a aplicação da Directiva 2008/52/CE, (2016/2066 (INI)), de 27.6.2017, A8-0238/2017.

UNIÃO EUROPEIA. Tratado sobre o Funcionamento da União Europeia - TFUE. Disponível em: https://europa.eu/europeanunion/sites/europaeu/files/eu_citizenship/consolidatedtreaties_pt.pdf\#page $=125$ 